\title{
FEMINISMO Y DISCAPACIDAD
}

José Luis Sánchez Tierra

Universidad de Sevilla

jossantie@gmail.com

Recibido: 09-02-2010

Aceptado: $26-03-2010$

\section{Resumen}

Históricamente se ha asociado la discapacidad a lo defectuoso, lo imperfecto, etc. La sociedad, lejos de asumir el problema de la discapacidad, lo redujo al ámbito de lo individual, negándose a asumir la parte de la responsabilidad que le corresponde. Mientras, filósofos y científicos, en su búsqueda de la "universalidad", ante el problema de la discapacidad, profirieron la acusación de marginal, acuñando el término "normal" como base paradigmática de una pseudociencia patriarcal que, de forma paralela, imprimía en la mujer la imagen de lo naturalmente incompleto e incapacitado, inferior al hombre en inteligencia y moral, relegándola a labores asistenciales. Algunos enfoques feministas, reconociendo paralelismos con el problema de la discapacidad, lejos de ignorarlo, lo asumen, saliendo beneficiados, al optar por la liberación y la inclusión en sus más amplias cotas.

Palabras clave: discapacidad, feminismo, mujer, exclusión, capacidades, asistencia, inclusión, justicia, horizontalidad, devaluación, sociedad, ciencia, salud, tradición, problemas, igualdad. 


\begin{abstract}
Historically, disability was associated to defective, imperfect, etc. The society, far from assume the problem of disability, reduced it to the scope of the individual, refusing to assume the part of responsibility that it's entitled. Meanwhile, philosophers and scientists, in their search of the "universality", before the problem of the disability, uttered the charge of marginal, coining the term "normal" as a paradigmatic basis of a patriarchal pseudoscience that, in a parallel way, printed on woman the image of naturally incomplete and disabled, inferior to man in intelligence and morals, relegating her to care work. Some feminist approaches, recognizing parallelisms with the problem of disability, far from ignoring, assume it, being better off with it, by opting for liberation and inclusion in their broadest dimensions.
\end{abstract}

Key words: disability, feminism, woman, exclusion, capabilities, assistance, inclusion, justice, levelness, devaluation, society, science, health, tradition, troubles, equality.

«La mujer, en casa y con la pata quebrada»

Refrán popular

"Ninguno de tus descendientes en cualquiera de sus generaciones, si tiene un defecto corporal, podrá acercarse a ofrecer el alimento de su Dios" (Lev. 21, 17-20).

\title{
1. Introducción
}

La pertinencia de la cuestión: ¿cuál es la relación entre el feminismo y el problema filosófico de la discapacidad?

La cuestión de la discapacidad, lejos de restringirse a un solo ámbito del pensamiento, transita todas sus ramas. Pero resulta obvio que dentro de este transitar ha tenido compañeros de viaje que le han salido al paso, recorriendo terrenos comunes que competen a esta patria compartida que es el ser humano. Sin embargo, la filosofía 
tradicional no ha parecido prestar mucha atención a la existencia -y a la experiencia- de personas con discapacidades físicas o cognitivas, y cuando lo ha hecho ha supuesto motivos para la exclusión. Lo que podríamos denominar como «modelo tradicional»o «excluyente»se basa en la entera atribución del problema de la discapacidad al ámbito individual, es decir, a la persona en concreto, basándose en una política de beneficencia que podían o no llevar a cabo los ciudadanos «normales», y negando la parte de atribución del problema que corresponde a la sociedad. Por desgracia muchos discapacitados experimentan esto como su propia condición existencial; escribe Oliver, M. (1990) en su obra The politics of disablement:

“Todos los discapacitados experimentan su condición de tales como una limitación social, sea que estas limitaciones se produzcan como consecuencia de los entornos arquitectónicos inaccesibles, de la incapacidad del público en general para usar el lenguaje de signos, de la carencia de material de lectura en braile o de las actitudes públicas hostiles hacia personas con deficiencias no visibles" (Barton, 1998: 24-25).

A continuación expongo algunas ideas de autores tradicionales que afianzan lo expuesto:

- El proyecto eugenésico de Platón (2003: §459d-460c) imponía que « [...] la necesidad de que los mejores "cohabiten" con las mejores tantas veces como sea posible y los peores con las peores al contrario; y si se quiere que el rebaño sea lo más excelente posible, habrá que criar la prole de los primeros, pero no la de los segundos. Todo esto ha de ocurrir sin que nadie lo sepa, excepto los gobernantes.

[...] Pues bien, tomarán, creo yo, a los hijos de los mejores y los llevarán a la inclusa, poniéndolos al cuidado de unas ayas que vivirán aparte, en cierto barrio de la ciudad; en cuanto a los de los seres inferiores -e igualmente si alguno de los otros nace lisiado- los esconderán, como es debido, en un lugar 
secreto y oculto». Este "secretismo" de la discapacidad por parte de Platón (2003: §407e) se fundamentaba en que «quien no es capaz de vivir desempeñando las funciones que le son propias no debe recibir cuidados, por ser una persona inútil tanto para sí mismo como para la sociedad».

- Aristóteles (2005: 1335b) aboga por el infanticidio: « [...] Debería haber una ley que impida la crianza de niños deformes».

- Si tenemos en cuenta cómo las diferentes discapacidades han sido vistas únicamente o bajo un «modelo médico»-que las atiende todas como si de una enfermedad se tratase- o como una asistencia deshonrosa -poco deseada por el asistente-, carga para la patria, etc. encontraremos un nuevo sentido a las palabras de Séneca -y al tema de la eutanasia- cuando escribe en sus Cartas: «El sabio se separará de la vida por motivos bien fundados: para salvar a la patria o los amigos, pero igualmente cuando esté agobiado por dolores demasiado crueles, en casos de mutilaciones o de una enfermedad incurable. [...] no se dará muerte, si se trata de una enfermedad que puede ser curada y no daña al alma; no se matará por los dolores, sino cuando el dolor impida todo aquello por lo que se vive [...] prefiero matarme a ver cómo se pierden las fuerzas y cómo se está muerto en vida [...] no hay que huir de la vida sino saber dejarla »(Gafo, 1990: 119).

- Los «contractualistas clásicos» asumieron que los agentes contratantes eran más o menos iguales en capacidad y aptos para desarrollar una actividad económica productiva, impidiendo la inclusión de personas con deficiencias en el grupo de los que deben escoger los principios políticos básicos, por lo tanto nunca formaron, plenamente, parte de la esfera pública. La exclusión de personas con deficiencias y discapacidades de la situación del contrato es un rasgo estructural de las teorías del contrato social, no estar en el grupo de los electores significa no estar incluido (como no sea de un modo derivado o 
ulterior, que provocará problemas de justicia) entre aquellos para quienes se eligen los principios.

- Hume (2008), a pesar de no ser contractualista -no estableciendo que aquellos que diseñan las reglas de justicia deben pertenecer al mismo grupo que las personas para quienes se diseñan-, su exclusión de las personas con discapacidad y las mujeres deriva de su insistencia en la relativa igualdad de las facultades como una de las «circunstancias de la justicia». A pesar de su énfasis en los buenos afectos, defiende que el despotismo de los más fuertes respecto de los más débiles siempre carecerá de la decencia más básica.

- Kant (Nussbaum, 2007) elabora su doctrina de los derechos prepolíticos partiendo de la igualdad aproximada de las partes del contrato en el estado de naturaleza, dividiendo a los ciudadanos en dos categorías, una «activa», que participa en la política y las elecciones sociales, y otra «pasiva», al no poder mantenerse por su propia industria. En el contrato de Kant, el grupo de las partes contratantes son imaginadas como «libres, iguales e independientes», coincidiendo con el conjunto de ciudadanos para los que se escogen los principios políticos, ello implica que las personas que no puedan mantenerse por su propia industria (incluyendo mujeres y niños) carecen de personalidad civil por no ser independientes, siendo ciudadanos «pasivos», y descalificados para los derechos políticos, no pudiendo participar en plena igualdad en la creación de las instituciones políticas, ni siquiera una vez que han sido creadas por el contrato inicial. El modelo de contrato kantiano es una puesta en práctica de un modelo de razón excesivamente idealizado que excluye a las personas con graves deficiencias mentales; de hecho, su concepción política de la personalidad requiere un elevado grado de racionalidad (moral y prudencial) que permita que las partes del contrato social sean más o menos iguales en poder y capacidad, permitiéndose el beneficio mutuo como objetivo buscado al optar por la cooperación. 
- Rawls distingue entre las partes que se encuentran en la Posición Original y los ciudadanos que forman parte de la sociedad diseñada, en último término, por los miembros de la Posición Original como «representantes». Las capacidades mentales y físicas se sitúan dentro del margen de lo «normal» según el modelo idealizado de razón que expone Kant-, de modo que las partes diseñan principios para ciudadanos que no padecen deficiencias graves (Nussbaum, 2007).

Como hemos podido observar, a lo largo de la historia de la filosofía, se ha hecho epojé o barbarie del problema de la discapacidad -sobre todo de las mentales- a la hora de tratar asuntos políticos, éticos o sociales. El por qué parece sencillo, de hecho peca de simplicidad: la cultura, generalmente, ha asociado la discapacidad a lo defectuoso, lo insuficiente, lo imperfecto, lo contranatura... es decir, con todo aquello de lo que huye la filosofía, sus "pendientes resbaladizas", el terror de toda filosofía práctica, un tema plural y heterogéneo que -supuestamente- resta claridad y simpleza a todo intento de construcción de una teoría unitaria; mandando al traste, no solo la tradición, sino todo aquello que la filosofía a lo largo de su historia ha intentado trascender o superar, sembrando la duda:

\footnotetext{
“Several years ago, in separate articles and without referente to each other' work, Ron Amundson, Gregory Kavka, and Susan Wendell, all philosophers with disabilities, remarked with dismay that contemporary philosophy alludes to disability primarily in discussions of whether to kill, or to let die, fetuses, neonates, or elderly individuals with disabling conditions. Philosophy thus has been inclined to ignore the majority of people who disabilities. Do their claims to be recognized compel us to revise our philosophical expectations about the levels of physical, sensory, and cognitive performance we take to be crucial for
} 
exercising moral responsibility and participating in civic life?"1 (Silvers, Wasserman y Mahowald, 1998: 142-143).

Para muchos de los filósofos tanto tradicionales como contemporáneos la salvación de su corpus ha pasado por no plantearse esta pregunta, alejarla de sus nociones básicas, pues es dinamita pura que hace tambalearse a los cimientos de la "cultura" occidental. ¿Quién se atreverá a enfrentarse a la pregunta?, ¿quién además de los discapacitados alzará su estandarte? ... deberá ser alguien que sienta cierta identificación o cercanía, alguien también en situación de exclusión, capaz de en su liberación arrastrar la pregunta por la "historia de los ocultos". Las concepciones tradicionales que han guiado el conocimiento epistemológico no sólo han sido crueles con los discapacitados, sino también con otro sector de la población. Las mujeres solían sufrir las mismas descalificaciones que los discapacitados, ambos condenados al silencio:

«El esclavo está absolutamente privado de voluntad; la mujer la tiene, pero subordinada; el niño sólo la tiene incompleta. Lo mismo sucede necesariamente respecto a las virtudes morales [...] Reconozcamos, pues, que todos los individuos de que acabamos de hablar, tienen su parte de virtud moral, pero que el saber del hombre no es el de la mujer, que el valor y la equidad no son los mismos en ambos, como lo pensaba Sócrates, y que la fuerza del uno estriba en el mando y la de la otra en la sumisión [...]Y así, en

\footnotetext{
${ }^{1}$ Traducción propia: «Hace varios años, en artículos separados y sin referencias a cada una de las demás obras, Ron Amundson, Gregory Kavka, and Susan Wendell, todos filósofos con discapacidades, observaron consternados que la filosofía contemporánea alude primariamente a las discapacidades en discusiones sobre si hay que matar, o dejar morir, fetos, recién nacidos, ancianos individuos con condiciones de discapacidad. Así pues, la filosofía se ha inclinado a ignorar a la mayoría de las personas que poseen discapacidades. ¿Hacer caso a sus reclamaciones de reconocimiento nos llevan a revisar nuestras expectativas filosóficas sobre los límites de la física, y el rendimiento - la performatividad, el hacer- sensorial y cognitivo que tomamos como necesario para ejercer la responsabilidad moral y participar en la vida cívica?».
} 
resumen, lo que dice el poeta [Gorgias] de una de las cualidades de la mujer: “Un modesto silencio hace honor a la mujer”» (Aristóteles, 2005).

En Aristóteles, al igual que en muchos filósofos griegos, encontramos una visión de la mujer basada en una perspectiva que podríamos denominar como pseudocientífica. La mujer, en lo que a su capacidad reproductiva refiere, era vista como la tierra y el hombre era como la semilla, él era el elemento activo -representando la fuerza- y ella el pasivo, lo cual reforzaba en la mujer el carácter peyorativo de no poseer facultades para el desarrollo de la moral o la inteligencia. Esta reducción pseudocientífica de la reproducción humana viene acompañada por el encierro o cercamiento de "esas tierras" a las que llaman "mujer", consideraba a la mujer tan niña, tan infantil, tan falta de intelecto etc., que no se le dejaba ni tan siquiera hacer cosas tan cotidianas como ir a la compra o cocinar (cosa que sí podían hacer algunos esclavos), se le permitía, eso sí, servir la mesa a su esposo. Dicho "entierro" doméstico da como consecuencia la identificación de la mujer con la blancura, la cual ha sido considerada a lo largo de la historia símbolo de decencia -o eslogan de detergentes-, no viéndose que realmente es todo lo contrario: el símbolo de una larga indecencia por parte del hombre, el ver a la mujer como a un recluso.

La educación, la historia, y en definitiva la cultura, han conservado la pseudociencia griega en la cual se funda una cultura patriarcal, este hecho, hace que con el paso de los siglos, en muchísimas ocasiones, cualquier tipo de avance social o político haya pasado, no ya por encima -ya que no había resistencia que saltar-, sino de largo, sin inmutarse, por la vera de la mujer. Un ejemplo claro lo encontramos en los ideales ilustrados de libertad e igualdad, los cuales se llevaron a cabo de forma unilateral y exclusivamente por el género masculino. En Rousseau (1995), sobre todo en su obra el Emilio, encontramos cómo -a la par que los griegos aunque con menor radicalización- sostiene la superioridad natural y moral del hombre, elaborando desde este punto de partida dos modelos de educación totalmente diferenciados. El hombre asume el papel de neutralizador de la "peligrosa naturaleza femenina", enclaustrada en 
el ámbito doméstico, mientras se adjudica todos los derechos y deberes de un espacio público.

En resumen: la mujer se asemejaba a la imagen del discapacitado, del "incompleto", de naturaleza inferior y demás [des]calificativos. Se le negaba la razón moral, aquella que Kant pide como necesaria en su concepción política de la personalidad y que se da por supuesta a las personas «normales». No sólo se le niega a la mujer cierto saber, valor o equidad, sino que además se la somete a la "tutela" del varón; a ellas, al igual que a los discapacitados, no se les ha tenido por personas «libres, iguales e independientes». Tanto las mujeres como los discapacitados, sobre todo mentales, tenían coartado el espacio público, sus "fueros" se restringían a la privacidad del espacio doméstico, y en el peor de los casos, cuando una discapacidad era incomprendida o hería la supuesta "sensibilidad ciudadana", se la ocultaba del mundo:

"Por exclusión aniquiladora se entiende que, junto a la integración utilitaria -la persona con discapacidad psíquica como recadero o pregonero, y con discapacidad física como zapatero o sastre-, existía paralelamente otra perspectiva de exclusión pasiva o activa de las personas con discapacidad, particularmente con retrasos o alteraciones psíquicas. Son todavía motivo de atención en estos últimos años el descubrimiento de adultos con discapacidad mental o plurideficiencias que han sido ocultados y encerrados en su hogar durante décadas, sufriendo un trato vejatorio como animales. La exclusión pasiva era el internamiento en asilos u hospitales psiquiátricos o, en todo caso, el abandono de la responsabilidad sobre estas personas" (Casado, 1991: 51).

Otro de los vínculos que ha unido a discapacitados y mujeres es el de la asistencia, estrechamente asociada a la justicia de género:

"[la primera cara del problema se refiere a cuál sería un trato justo para las personas con deficiencias que necesitan situaciones sociales atípicas para una 
vida plena] [...] aparte, una sociedad justa tomaría en consideración la otra cara del problema, es decir, las cargas que todo eso supone para los cuidadores de las personas dependientes [...] Esta cuestión está estrechamente asociada a la justicia de género, pues la mayoría de las veces la asistencia a las personas dependientes va a cargo de las mujeres. Más aún, la mayor parte del trabajo de asistencia a las personas dependientes no está retribuido y no es reconocido como tal por el mercado [...] no podemos ignorar ni posponer estos problemas con el argumento de que sólo afectan a un número reducido de personas" (Nussbaum, 2007: 111-112).

Si buscamos una sociedad justa debemos hacer frente a los problemas de género y discapacidad, asumirlos, no ignorarlos, y reconocer el valor de las personas que han permanecido «en aquel suspenso que es la noche», ya que de esas oscuridades «puede salir la luz» de una nueva forma de pensar. Frente a la marginalidad de un logos extraño, de un movimiento histórico que oculta, del silencio de lo privado, de una ciudadanía política dividida en clases, etc. se ha potenciado un pensamiento novedoso, obligado a romper con la tradición y «tentación», obligado a la poiesis, a la creación, al feminismo:

"Un pensamiento que se hace poesía y sale de lo no dicho, que es maravilla y “acción de gracias", deja al ser en toda su transparencia, a la espera de palabras nuevas, capaces de corresponder al decir originario, con el valor de permanecer en aquel suspenso que es la noche de la que puede salir la luz. Si el logos permanece firme en lo universal y lo neutro, tendrá necesidad de inventar un nuevo lenguaje para expresar la vida; más bien será la metáfora que suscite intuiciones sin ocultar su sentido, que trate de expresar sin delimitar, remitiendo siempre a algo de otro que esté debajo, al lado o más allá de lo dicho.

Para las mujeres esto significa evitar la tentación "machista" del pensar como posesión ("dar nombre”), para tratar de descubrir el sentido radicalmente 
humano de lo que antes estaba reprimido porque era considerado femenino: la escucha, la obediencia, la espera, la renuncia, superando la tentación -que antecede al pensamiento y sucede al lenguaje y a las ideologías- de obligar al mundo a someterse al dominio del pensamiento" (Di Nicola, 1991: 180-181).

Este feminismo creador, encontró junto a las sombras que habitaba -a su verael problema de la discapacidad, y no queriendo dejarlo de lado lo asumió. Gracias a este hecho, en el último medio siglo, se han gestado diversas teorías sobre las [dis]capacidades humanas que dan un sentido diferente a la palabra igualdad. Se ha cuestionado la preeminencia asignada a lo que tradicionalmente hemos llamado «normal», y se ha cuestionado la devaluación conceptual a la cual se han visto sometidas ciertas condiciones físicas o psíquicas en nombre del buen funcionamiento de la ciencia; como insiste Dominique Lecourt en su introducción a una obra de George Canguilhem :

«"sin los conceptos de normal y de patológico el pensamiento y la actividad del médico resultan incomprensibles" (Canguilhem, G. La connaissance de la vie, pág. 153). La terapéutica se presenta siempre como un intento por restaurar lo "normal". Ahora bien, contra la idea positivista según la cual lo normal sería un promedio estadístico, Canguilhem -en nombre del vitalismo que defiendeinsiste en que esa concepción entraña un tratamiento del ser vivo como si fuese un sistema de leyes en lugar de un "orden de propiedades" específicas. Orden en el doble sentido del término, porque de acuerdo con Canguilhem lo esencial de lo normal consiste en ser "normativo", es decir en instituir normas y ser capaz de cambiar las normas que ha instituido [...] Canguilhem habla del “orden de la vida" que también debe interpretarse como exigencia del ser vivo [...], es preciso advertir que esa primacía se apoya, en definitiva, sobre la idea de que la vida, actividad polarizada, indica las vías no sólo para la restauración 
de su estado normal sino para su propia conceptualización» (Lecourt, 1984: XXVII).

Las "normas" instituidas por la "cultura" tradicional para decidir que es lo "normal" y por tanto que marca la "norma" ha ahogado a multitud de sectores, que se han visto abocados a la marginalidad, pero sobre todo a mujeres y discapacitados. Debemos no solo indagar, sino también participar en la formación conceptual de lo "normativo" para evitar problemas de justicia, la "norma de lo normal" no puede constituirse mediante la simple observancia del modelo que aporta la tradición. Muchas pensadoras feministas se trasladan hacia este cambio de interés, comprometiéndose con la reforma de la idea filosófica de inclusión o justicia, como es el caso de Martha C. Nussbaum y su Enfoque de las Capacidades. Es innegable la familiaridad del problema de la discapacidad con respecto a algunos enfoques feministas -sobre todo en cuestiones de ética y teoría de la justicia-, de hecho, muchos de estos enfoques se han visto beneficiados al incluir dicho problema ${ }^{2}$. El compromiso feminista con las ideas de liberación, auto-afirmación e inclusión debe ser lo más amplio posible, incluyendo problemas como los derechos de los discapacidad, si no fuera así pecaría de criticar una discriminación que también acomete.

\section{La aceptación de la discapacidad}

Dentro de la filosofía, la discapacidad, la deformidad y la enfermedad han aparecido múltiples veces para desafiar la aplicación de presupuestos teóricos y prácticos. La resistencia de la discapacidad a ser subsumida en una teoría filosófica la

\footnotetext{
${ }^{2}$ En el «Enfoque de las Capacidades» de Martha C. Nussbaum (2007), la discapacidad, lejos de ser un problema o posible refutación de su teoría (como sucede con Rawls), refuerza la competencia de la misma; al tratar bajo una perspectiva de igualdad, que difiere de toda la tradición, la pluralidad de las diferentes individualidades.
} 
encontramos en Platón y su proyecto eugenésico; en Hume, quien no trata a las personas con discapacidades ni en su «teoría de la percepción» ni en su teoría de las «circunstancias de justicia», en esta última debido a que las partes tienen que ser aproximadamente iguales en sus capacidades; en los principales teóricos del «contrato social» quedan excluidos debido a ideas de beneficio mutuo e igualdad aproximada; en Rawls (1997), aunque se trata el tema de la discapacidad, este es pospuesto a un estado posterior en el cual ya están definidos con anterioridad los principios básicos de justicia para todos los ciudadanos, lo cual atenta contra la integración de la discapacidad dentro de la Posición Original, es decir de la de elección de las normas básicas de justicia; etc.

Igualmente, las pensadoras feministas se preguntaron por su exclusión de la tradición filosófica, por ello se han visto forzadas a poner remedio a una filosofía donde prevalece una sangrante indiferencia ante la forma en que las mujeres, y los discapacitados habitan el mundo; el feminismo aportará de esta manera unas nuevas lentes sobre las que observar el problema de la discapacidad: frente a los esquemas de "verticalidad" y diferencias de poder, se opondrá un esquema basado en la "horizontalidad" y la cooperación, la inclusión y la igualdad.

Mujeres y discapacitados han recibido un trato injusto, se les ha devaluado para múltiples prácticas, una de las causas de este hecho ha sido la "devaluación de los cuerpos". Podemos observar como en múltiples culturas se ha tendido a la estigmatización del cuerpo femenino debido a un clima conceptual que privilegiaba el rendimiento corporal masculino. El desprecio hacia la condición femenina dentro del mundo griego lo podemos encontrar en numerosos fragmentos de su literatura; un ejemplo de ello lo encontramos en la Ilíada, cuando Aquiles despoja al cadáver de Héctor de su armadura aparecen expresiones referidas a la "blandura" de su cuerpo ${ }^{3}$, más apropiadas para describir el cuerpo de una mujer que el de un guerrero (Madrid, 1999), suponiendo una ofensa la identificación con lo femenino. En innumerables ocasiones se alude a la «bella», «blanca», «tierna»y «delicada» piel (o carne) -símbolo

\footnotetext{
3 «Ciertamente Héctor es mucho más blando de tocar por ambos lados que cuando quemó las naves con ardiente fuego» (Homero, 2005, Canto XXI, §373).
} 
de la iconografía femenina- como insulto, síntoma de cobardía (poca umbría), debilidad, falta de respeto hacia el contrario, etc. ${ }^{4}$

Se devalúa el cuerpo de la mujer, se la considera menos "virtuosa", por ello corre un mayor riesgo a ser considerada "deficiente" o "disminuida" en cuanto a fuerza física, mental o salud. A esto, tenemos que sumar cómo el imaginario tradicional -y androcéntrico- da la mujer una labor de cuidadora, restringiéndola al ámbito privado, ya que se la consideraba en desventaja para participar en el ámbito público; ello ha acercado a la mujer a sectores relacionados con la atención a discapacitados.

Cuando el feminismo se preguntó sobre la discriminación de la mujer y examinó los principios que le impedían realizar su propia vida tuvieron que enfrentarse a una cuestión: si los principios de la filosofía tradicional que dan como resultado su marginación son modificables, es decir debidos a un acuerdo social, o son biológicos e inmutables (basados en su constitución corporal, mental, etc.). La respuesta fue clara: la sociedad es una fuente de limitación para la mujer. Esta teoría resulto extrapolable al problema de las deficiencias, la cuestión ya no pasaba por dar razones para su exclusión acudiendo a la corporeidad de las deficiencias, se exigía otro enfoque:

“A lo largo de nuestra reciente historia el concepto de discapacidad y el modelo de atención aplicado derivado de cada conceptualización ha variado:

\footnotetext{
4 «— ¡Argivos! No desmaye vuestro impetuoso valor. El padre Zeus no protegerá a los pérfidos; como han sido los primeros en faltar a lo jurado, sus tiernas carnes serán pasto de buitres y nosotros nos llevaremos en las naves a sus esposas e hijos cuando tomemos la ciudad» (Homero, 2005, Canto IV, §234); « [...] apuntando a la cabeza de Héctor, blandió y arrojó la ingente lanza, que fue a dar en la cima del yelmo; pero el bronce rechazó al bronce, y la punta no llegó al hermoso cutis [...] Héctor tornó en su sentido, subió de un salto al carro, y dirigiéndolo por en medio de la multitud evitó la negra muerte. Y el fuerte Diomedes, que lanza en mano le perseguía» (Homero, 2005, Canto XI, §349); «—_Ayante lenguaz y fanfarrón!, ¿qué dijiste? así fuera yo hijo de Zeus, que lleva la égida, y me hubiese dado a luz la venerable Hera y gozara de los mismos honores que Atenea o Apolo, como este día será funesto para todos los argivos. Tú también morirás si tienes la osadía de aguardar mi larga pica: ésta te desgarrará el delicado cuerpo; y tú, cayendo junto a las naves aqueas, saciarás de carne y grasa a los perros y aves de la comarca troyana.» (Homero, 2005, Canto XIII, §824).
} 
- Desde el modelo "tradicional", en el que la discapacidad quedaba por entero atribuida a la [naturaleza] de la persona y la política era de beneficencia (modelo excluyente).

- Pasando por el modelo medicalizado, que tomaba a la discapacidad como objeto de intervención dando lugar a políticas rehabilitadotas y considerando a la persona como paciente.

- Al modelo social, que partiendo del concepto de discapacidad basado en la interacción individuo-entorno, debe diseñar políticas centradas en el ejercicio de los derechos considerando a la persona con discapacidad como ciudadano y por tanto sujeto de participación activa.

Este modelo social nos está planteando nuevos retos que empiezan a tener su reflejo a nivel normativo y desde luego han de tenerlo a nivel práctico, a nivel de las políticas concretas" (Campoy, 2004: 247).

La diferencia biológica entre hombres «normales», mujeres y discapacitados es un hecho innegable, pero lo controvertido no es esto, sino el debate sobre si las limitaciones funcionales asociadas a una determinada discapacidad o a un determinado género están justificadas o suponen un hecho desfavorable. El Modelo Social implica una apuesta por la integración, una concepción de persona más abierta y más plural, una aceptación del problema de la discapacidad que impide -como hizo la tradiciónpasar por encima de él y la jerarquización de los cuerpos.

\section{Inclusión, funcionamiento y capacidad}

El Modelo Social que hemos especificado para cumplir con sus objetivos, debe primeramente abandonar las epistemologías «tradicionales»-con sus ideas de "naturaleza" estereotipada- y rechazar los modelos sociales basados únicamente en el cuidado (el Modelo Médico); en segundo lugar debe rechazar que un cierto nivel de 
funcionamiento considerado como «normal» pueda imponer un sistema de evaluación y conducta, ya que debemos tener en cuenta que las variaciones y asimetrías en las necesidades físicas no son casos aislados (o anormales), sino un hecho general de la vida humana: la asistencia es parte de nuestra vida cuando somos niños, sufrimos algún tipo de accidente o deficiencia temporal, se nos complica un embarazo, envejecemos, etc.

La ciencia tiende a medir la realidad con escalas que reducen la pluralidad a unidad. Al tenerse que calibrar y valorar los diferentes atributos, muchas particularidades resultan devaluadas, desviadas, o anormales. Foucault (1992: 187-188) encontró en esta mirada normalizadora cinco operaciones: comparación, diferenciación, jerarquización, homogeneización y exclusión:

“[La razón normalizadora] remite las acciones individuales a un todo que es al mismo tiempo un campo para la comparación, un espacio de diferenciación y el principio de una regla que debe seguirse. Dicha razón normalizadora diferencia a unos individuos de otros en términos de la siguiente regla general: que la regla se haga para funcionar como umbral mínimo, como un término medio a ser respetada o un óptimo hacia el que nos debemos dirigir. Tal razón mide en términos cuantitativos y jerarquiza en términos de valor las habilidades, el nivel, la "naturaleza" de los individuos. Introduce, a través de esta media "valorizante", el grado de conformidad que debe alcanzarse. En fin, trazar el límite que habrá de definir la diferencia respecto de todas las diferencias, la frontera externa de lo anormal. [...] La penalidad perfecta que atraviesa todos los puntos, y controla todos los instantes de las instituciones disciplinarias, compara, diferencia, jerarquiza, homogeniza, excluye. En una palabra, normaliza”.

Una descripción de la realidad biológica, por muy exhaustiva que sea, no determina nuestro nivel de funcionamiento, no puede establecer una «norma». El nivel de funcionamiento que una persona puede alcanzar no depende únicamente de sus 
propias capacidades individuales: depende también de las estructuras sociales, y de cómo una sociedad puede adaptarse a las necesidades propias de cada persona. La falta de movilidad de una persona que no puede caminar no se debe únicamente a sus características físicas, es también una función de la sociedad fomentar la construcción de rampas que faciliten una cierta libertad de movimiento. A su vez, un mercado de trabajo flexible, que asuma medidas positivas para la protección de la mujer en su lugar de trabajo y propicie otras que hagan que los hombres asuman con naturalidad su responsabilidad en el ámbito familiar, ayudará al pleno funcionamiento de la mujer en el espacio público, no teniendo que verse obligada a elegir entre tener un hijo o un trabajo, ni teniendo que abandonar su puesto de trabajo para atender de forma exclusiva las necesidades domésticas o de cuidado.

El Modelo Social centra su atención en cómo debe funcionar una sociedad para no oprimir a ciertos colectivos. Esto no quiere decir que las disfunciones sean totalmente impuestas por la sociedad, pero sí que la sociedad asume su intento de proporcionar un determinado nivel de funcionamiento. En este punto podemos encontrar los mayores problemas:

"Quality of life is conceived in a way that directly conflicts with the Social Modelo of disability, and the conflict is deeply rooted in biomedical ethical discussion. One particular application will be discussed: the reduction of health care for disabled people because of their allegedly low quality of life", (Amundson 2005: 101).

A este problema podemos sumar otros como el derecho al aborto, la eutanasia, las capacidades que una persona debe poseer para darle a un niño en adopción, etc.

\footnotetext{
${ }^{5}$ Traducción propia: «La calidad de vida es concebida de una manera que entra directamente en conflicto con el Modelo Social de discapacidad, y el conflicto está profundamente arraigado en la discusión ética de la biomedicina. Una particular aplicación que se debatirá: la reducción de la atención a la salud para personas discapacitadas a causa de su supuestamente baja calidad de vida».
} 
Problemas que nos hacen dudar entre si debemos asumir completamente el Modelo Social o volver la vista hacia el Modelo Médico o inclusive, en determinados casos hacia uno más «tradicional». El Enfoque de las Capacidades ofrecido por Nussbaum nos da un jugoso tratamiento del problema:

"When we think of health, for example, we should distinguish between the capability or opportunity to be healthy and actual healthy functioning: a society might make the first available and also give individuals the freedom not to choose the relevant functioning"6 (Nussbaum, 2000: 14).

Nussbaum (2007: 91), al proteger el pluralismo, insiste en que la finalidad política debe ser la capacidad y no el funcionamiento. Y aunque reconoce que en el terreno de la salud «los defensores del Enfoque de las Capacidades discrepan sobre si la finalidad debe ser la capacidad o el funcionamiento», defiende que «debería darse un amplio margen a las personas para llevar un estilo de vida saludable, pero la elección debería corresponderles siempre a ellos; no se debería penalizar tomar decisiones contrarias a su salud». La reducción de la atención a la salud para personas discapacitadas a causa de su baja calidad de vida sería un problema relacionado con el funcionamiento, y podría pecar de cierto utilitarismo. El Enfoque de las Capacidades de Nussbaum dejaría la posibilidad de elección del lado del sujeto que sufre, si quiere o no ciertas atenciones. En el tema del aborto no está tan claro el enfoque que se podría tomar, ya que hay que discutir primero en qué momento de la gestación se consideraría al feto sujeto de derecho; lo que sí parece estar más claro es que hay que dotar a las mujeres de los medios que puedan capacitarlas a llevar a cabo el alumbramiento, facilitar el mismo no obligándolas a trabajar cuando la gestación esté en un estado

\footnotetext{
${ }^{6}$ Traducción propia: «Cuando pensamos en la salud, por ejemplo, debemos distinguir entre la capacidad o la oportunidad de estar sanos y funcionar de una forma realmente saludable: una sociedad puede hacer lo primero disponible y también dar individualmente la libertad de no elegir el funcionamiento pertinente».
} 
avanzado, e intentar que elijan libremente sin la presión del utilitarismo económico, o dicho más llanamente, de la falta de medios para ejercer la maternidad.

\section{El enfoque de las capacidades}

Las teorías tradicionales no parecen ajustarse al Modelo Social que hemos especificado: más centrado en las capacidades. Parece ser que necesitamos de una teoría filosófica que se adapte al mismo, dando cabida a mujeres, discapacitados y una amplia variedad de sectores de la población con formas de vida diferenciadas; el Enfoque de las Capacidades parece ser el más acertado. Dicho enfoque ha sido desarrollado por diversas personas interesadas también en el feminismo, de hecho muchas ven el estudio de las capacidades como «the basis for fundamental political principles focuses on the lives of women in developing countries» ${ }^{7}$ (Nussbaum, 2000: XIII).

Amartya Sen (1985), fue el primero en desarrollar un enfoque de la pobreza en términos de capacidades, centrándose sobre todo en la medición del bienestar. Según Sen, lo importante para decidir si una persona es o no es pobre no son los bienes, sino las capacidades personales o el conjunto de funcionamientos factibles. Los bienes se analizan según sus características, éstas ayudan a la consecución de ciertas capacidades que son de gran utilidad para una vida digna. Por lo tanto, cuando se dice que una persona es pobre, lo que queremos decir es que se ve en la imposibilidad de realizar una serie de capacidades, sobre las cuáles se podría inclusive llegar a un acuerdo. Lo interesante de este punto de vista es que mientras que las capacidades son constantes, los bienes y recursos varían, y no al contrario, como ha sucedido en todos los modelos de la tradición, donde el bienestar se medía por referencia a los bienes y al PIB. Mediante este enfoque, podemos ver que en muchos casos lo que llamamos pobreza no es más que un síntoma de exclusión social, como lo es la visión tradicional de la mujer

\footnotetext{
${ }^{7}$ Traducción propia: «la base para unos principios políticos fundamentales centrados en la vida de las mujeres en países envías de desarrollo».
} 
como "mantenida" y el hombre como "cabeza de familia", y la exclusión social, el no poder desarrollarse en sociedad, no poder pasear sin barreras arquitectónicas, etc. es un problema de justicia básica, y no tanto de riqueza.

Este enfoque fue tomado por Nussbaum, que con alguna que otra distinción, le dio forma filosófica: como base para una teoría de derechos básicos de los seres humanos que deben ser respetados y aplicados por los gobiernos como requisito mínimo del respeto por la dignidad humana. Defendió que este tipo de teorías pueden llevarnos más lejos que las doctrinas del contrato social, e inclusive podríamos verla como extensión o complemento a la teoría de Rawls. El Enfoque de las Capacidades resulta ser una guía más sólida para legislaciones y políticas públicas, al ser la mejor forma para plantear un mínimo social básico. En ella, se presentan las capacidades como fuente de los principios políticos para una sociedad liberal y pluralista, por ello su contexto debería ser un liberalismo político que los convierta en fines específicamente políticos y los formule de un modo que evite toda fundamentación metafísica específica. La huida de toda concepción metafísica facilitará el consenso entre personas con concepciones distintas del bien. Las capacidades deberían atribuirse a todas las personas, para tratarlas así como fines, y no como medios, para ello hay un umbral para cada capacidad, por debajo del cual los ciudadanos no pueden funcionar de un modo auténticamente humano, la meta social: lograr que los ciudadanos se sitúen por encima de este umbral de capacidades.

Una lista de capacidades debe incluir una pluralidad de elementos no reductibles a términos de cantidades a disposición de un bien único y homogéneo, además se centra en qué son las personas efectivamente capaces de hacer. Una idea intuitiva básica del Enfoque de las Capacidades es la concepción de dignidad del ser humano, y de vida acorde con esa dignidad; vida que incluye un «funcionamiento auténticamente humano», en sentido marxista ${ }^{8}$. La propuesta de Nussbaum (2007) es la siguiente lista:

\footnotetext{
${ }^{8}$ Marx insistía en que las capacidades a las que tienen derecho los ciudadanos son muchas, y son oportunidades para actuar, no sólo cantidades de recursos, además los seres humanos poseen diversas capacidades de convertir los recursos en funcionamientos.
} 
Tabla 1. Las capacidades humanas básicas

\begin{tabular}{|c|c|}
\hline \multicolumn{2}{|r|}{ Las capacidades humanas básicas } \\
\hline 1. Vida & $\begin{array}{l}\text {-Poder vivir hasta el término de una vida humana (que merezca la pena vivirla) } \\
\text { de duración normal (sin muerte prematura). }\end{array}$ \\
\hline 2. Salud fisica & $\begin{array}{l}\text {-La buena salud incluye: salud reproductiva, alimentación adecuada y un lugar } \\
\text { adecuado para vivir. }\end{array}$ \\
\hline $\begin{array}{l}\text { 3. Integridad } \\
\text { física }\end{array}$ & $\begin{array}{l}\text {-Poder moverse libremente, estar protegido, oportunidad para la satisfacción } \\
\text { sexual y opciones reproductivas. }\end{array}$ \\
\hline $\begin{array}{l}\text { 4.Sentidos, } \\
\text { imaginación y } \\
\text { pensamientos }\end{array}$ & $\begin{array}{l}\text {-Poder usarlos de un modo «auténticamente humano», con una educación } \\
\text { adecuada que incluya: alfabetización, formación matemática y científica } \\
\text { básica... También poder usarlos para obras y eventos según propia elección. } \\
\text {-Usar la propia mente en libertad de expresión, así como libertad de prácticas } \\
\text { religiosas. } \\
\text {-Poder disfrutar de experiencias placenteras y evitar dolores no beneficiosos. }\end{array}$ \\
\hline 5. Emociones & $\begin{array}{l}\text {-Poder mantener relaciones afectivas con diferentes personas y objetos, poder } \\
\text { amar, dolernos por su ausencia, penar, experimentar ansia, gratitud y enfado } \\
\text { justificado. } \\
\text {-Que nuestro desarrollo emocional no quede bloqueado por el miedo y la } \\
\text { ansiedad. }\end{array}$ \\
\hline $\begin{array}{l}\text { 6. Razón } \\
\text { práctica }\end{array}$ & $\begin{array}{l}\text {-Poder formarse una concepción del bien y reflexionar sobre los propios planes } \\
\text { de vida, lo cual implica libertad de conciencia y observancia religiosa. }\end{array}$ \\
\hline 7. Afiliación & $\begin{array}{l}\text { a) Interacción social: poder vivir con y para otros (ser capaz de imaginar la } \\
\text { situación de otro). } \\
\text { b) Bases sociales de autorrespeto y no humillación: dignidad e igual valor } \\
\text { como disposiciones contrarias a la discriminación. }\end{array}$ \\
\hline $\begin{array}{l}\text { 8. Otras } \\
\text { especies }\end{array}$ & $\begin{array}{l}\text {-Poder vivir con otras especies y con el mundo natural una relación próxima y } \\
\text { respetuosa. }\end{array}$ \\
\hline 9. Juego & -Poder reír, jugar y disfrutar de actividades recreativas \\
\hline $\begin{array}{l}\text { 10. Control } \\
\text { sobre el propio } \\
\text { entorno }\end{array}$ & $\begin{array}{l}\text { a) Político: Poder participar de forma efectiva en las elecciones políticas, y } \\
\text { tener derecho a la protección de la libertad de expresión y asociación } \\
\text { b) Material: Poder disponer de propiedades en un plano de igualdad, tener } \\
\text { derecho al trabajo en un plano de igualdad (poder trabajar como ser humano, } \\
\text { ejercer la razón práctica y entrar en relaciones de conocimiento mutuo con los } \\
\text { demás trabajadores) y no sufrir persecuciones ni detenciones sin garantías. }\end{array}$ \\
\hline
\end{tabular}

Fuente: Nussbaum (2007: 88-89)

Cuestiones de género: de la igualdad y la diferencia. № 5, 2010 - ISSN: 1699-597X - pp. 407-432 
Muchos autores han comentado que el objetivo de Nussbaum es desarrollar un feminismo universalista:

\begin{abstract}
«Dando por supuesto un mundo en el que muchas mujeres carecen de apoyo en funciones fundamentales de la vida humana, y en el que la mayoría de ellas cuentan con capacidades menores a las de los hombres, el objetivo de Nussbaum es desarrollar un "feminismo universalista"» (Gough, 2007: 178).
\end{abstract}

\title{
5. Problemas en el enfoque de las capacidades
}

El Enfoque de las Capacidades es una más que sugerente propuesta de igualdad, extensible no sólo a cualquier sector poblacional en situación marginal, sino también a cualquier ser humano de forma individual. Aun así, este enfoque no carece de problemas y dificultades que han de ser enumerados, para así afrontarlos en pos de futuras reformulaciones que hagan a la teoría más consistente. Estos son algunos de los problemas:

- El enfoque iniciado por Sen (1985) -a diferencia de teorías contractualistas como la de Rawls (1997) - tiene una influencia práctica limitada, ello se debe a las dificultades de medición que implica una teoría basada en las capacidades. Resulta sumamente complicado convertir un concepto como las «capacidades» en un indicador operativo válido para medir el índice de realización de los objetivos a alcanzar por una pluralidad de individuos ampliamente diferenciada. Quizás estas sean las razones de que hoy día existan pocos 
estudios sobre la pobreza basados en las capacidades, es muy posible que tengamos que abandonar cualquier intento de medición en este tipo de teorías. ${ }^{9}$

- Si la lista de capacidades que desarrolla Nussbaum (2007) encuentra múltiples problemas en cuestiones de salud, mayor resulta el problema cuando introduce aspectos como el desarrollo de la imaginación, algo tan excesivamente intangible que resulta difícil ver su influencia en la calidad de vida. Parece como si las capacidades sólo cobrasen sentido cuando se carece completamente de ellas, sea por vivir en un Estado represivo, estar preso, etc.; quizás sólo a través de la existencia de algún estado de carencia grave adquieran su potencial crítico.

- Necesita de un punto de vista contractualista -como el de Rawls- para dirimir asuntos de la vida laboral como el uso del tiempo y la intensidad del trabajo.

- Una de las críticas más serias al Enfoque de las Capacidades desarrollado por Nussbaum viene de otra filósofa liberal feminista:

“Anne Phillips, quien afirma que el enfoque de capacidades tiene en su centro una agenda neo liberal; asegura que debido a que el enfoque de las capacidades de Nussbaum se concentra en los requerimientos mínimos necesarios, se aleja de los desafíos profundos de la lucha por la igualdad humana, no sólo entre mujeres y hombres, sino a través de grupos sociales tanto en el interior de las naciones o entre ellas. Este alejamiento, declara Phillips, “encaja con un cambio casi universal en la política social-democrática, donde el problema de la pobreza ha suplantado al problema de la desigualdad y las preocupaciones por la diferencia general de ingresos le ha dado paso a la garantía de un mínimo humano”. En

\footnotetext{
9 Aun así, deberíamos esforzarnos por encontrar ciertos criterios que ayuden a medir la desigualdad, la pobreza, la calidad de vida... en términos de capacidades. Aceptar estas dificultades en la medición ni mucho menos implica que el Enfoque de las Capacidades sea estéril teóricamente.
} 
otras palabras, el centro de atención material del enfoque de las 'capacidades' no aborda las desigualdades más absolutas y se aleja de la igualdad de derechos básicos. Otros críticos [Malhotra y Mather; Govindasamy y Malhotra; Kabeer] sugieren que el enfoque de capacidades hacia la justicia social reduce ésta a un asunto de acceso individual a los bienes públicos y a un proyecto de liberación individual, y no a un entendimiento de la manera como mujeres y hombres pueden construir sus intereses como parte de una colectividad social, mediante la interdependencia y no por la independencia” (Maitrayee, 2008: 17).

Si tomamos el Enfoque de las Capacidades como ideal regulativo, a partir del cual ir guiando un Modelo Social de salud alejado de la jerarquización de los cuerpos, más que problemas, encontramos retos a nivel práctico. Efectivamente, tal y cómo se ha enumerado más arriba: existe gran dificultad a la hora de medir las capacidades; a veces el enfoque de Nussbaum sólo es visible cuando las carencias son extremadamente graves; se necesitan modelos contractualistas en el mundo laboral y éstos pueden abogar por conductas poco aconsejables (aunque ampliamente rentables); y al no regularse de forma estructural la igualdad e interacción entre personas puede llegarse a comparar el ingreso económico con el mínimo humano, reduciéndose la justicia social al mero acceso a bienes públicos o de seguridad social. Pero estas dificultades no desechan el Enfoque de las Capacidades, lo que demuestran es algo que éste ya defiende, es decir: la idea de que las asimetrías son generales en la vida humana, tanto individualmente como a nivel de sociedades, creencias, sexo, cultura, etc. Lo que debemos hacer con los diferentes retos enunciados es asumirlos, y ponernos manos a la obra, pero conservando la premisa de que el desarrollo real de un país lo miden las capacidades y oportunidades que desarrolla, otra cosa muy diferente es el funcionamiento que un individuo realice, lo cual pertenece al ámbito de su libertad personal. Por ello, las políticas de salud, igualdad, trabajo, economía, etc., deben ir encaminadas hacia la facilitación del ejercicio de la ciudadanía, a nivel normativo y práctico, mediante políticas concretas que aseguren las capacidades humanas básicas. 


\section{BIBLIOGRAFÍA}

- Amundson, R. (2005): "Disability, Ideology, and Quality of Life. A Bias in Biomedical Ethics". En Wasserman, Wachbroit y Brickenbach (eds): Quality of life and human difference. Cambridge: Univ. Press, pp. 101-124.

- Aristóteles (2005). Política. Madrid: Alianza.

- Barton, L. (ed.) (1998): Discapacidad y sociedad. Madrid: Morata.

- Campoy Cervera, I. (2004): Los derechos de las personas con discapacidad: Perspectivas sociales, políticas jurídicas y filosóficas. Madrid: Dykinson, S.L.

- Casado, D. (1991): Panorámica de la discapacidad. Barcelona: Intress.

- Di Nicola, J. P. (1991): Reciprocidad hombre-mujer. Igualdad y diferencia. Madrid: Narcea.

- Foucault, M. (1992): Vigilar y Castigar: el nacimiento de la prisión. Madrid: Siglo XXI.

- Gafo, J. (1990): Eutanasia: el derecho a una muerte humana. Madrid: Temas para Hoy.

- Gough, I. (2007): "El enfoque de las capacidades de M. Nussbaum: un análisis comparado con nuestra teoría de las necesidades humanas". En Papeles de relaciones ecosociales y cambio global, $\mathrm{n}^{\mathrm{o}} 100$, pp.177-202.

- Homero (2005): Ilíada. Barcelona: Anagrama.

- Hume, D. (2008): Tratado de la naturaleza humana: autobiografía. Madrid: Tecnos.

- Lecourt, D. (1984): "La historia epistemológica de Georges Canguilhem". En Canguilhem, G.: Lo normal y lo patológico. Buenos Aires: Siglo XXI.

- Madrid, M. (1999): La misoginia en Grecia. Madrid: Cátedra.

- Mukhopadhyay, M. y Singh, N. (2008). Justicia de género, ciudadanía y desarrollo. Bogotá: Mayol.

- Nussbaum, M. (2000): Women and human development. Cambridge: Univ. Press. . (2007): Las fronteras de la justicia. Barcelona: Paidos. 
- Platon (2003): República. Madrid: Alianza.

- Rawls (1997): Teoría de la justicia. Madrid: Fondo de Cultura Contemporánea.

- Rousseau (1995): Emilio o de la educación. Madrid: Alianza.

- Sen, A. (1985): Commodities and capabilities. Amsterdam: North-Holland.

- Silvers, A.; Wasserman, D. y Mahowald, M. (1998): Disability, Difference, Discrimination: Perspectivas on Justice in Bioethics and Public Policy. Lanham: Rowman \& Littlefield Publishers. 